
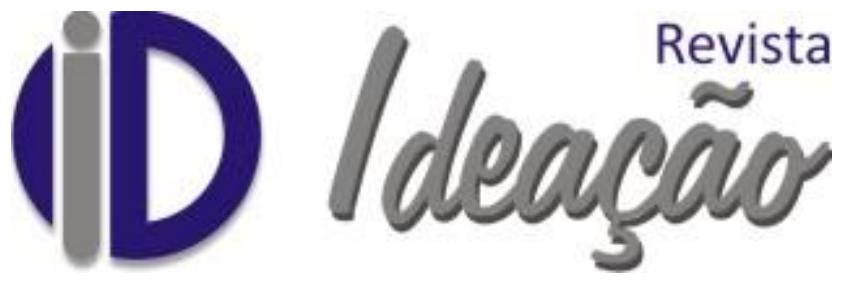

Universidade Estadual do Oeste do Paraná

Centro de Educação, Letras e Saúde

Campus de Foz do Iguaçu

ideacao@yahoo.com.br

Telefone: +55 45 3576-8100

\title{
PAULO FREIRE Y LA REVOLUCIÓN CUBANA. 1959-1997: DE LA HISTORIA INTELECTUAL A LA SOCIAL
}

DOI: 10.48075/ri.v23i1.26702

Felipe de J. Pérez Cruz ${ }^{1}$

RESUMEN: El artículo tiene por objetivo exponer la investigación realizada sobre los vínculos históricopedagógicos de Paulo Freire con la Revolución Cubana. Se utiliza una metodología cualitativa para precisar en tiempo, espacio y trascendencia de las relaciones objeto de estudio. Se evalúan los contextos de partida, el interesante mosaico de circunstancias internacionales y nacionales en que se movieron estas relaciones, las raigales luchas emancipatorias caribeñas, latinoamericanas y mundiales de la época, y el impacto del protagonismo histórico de Freire y de la Revolución Cubana, sus identidades, paralelos y confluencias.

Palabras-Clave: Freire; educación popular e revolución cubana.

\section{PAULO FREIRE E A REVOLUÇÃO CUBANA. 1959-1997: DA HISTÓRIA INTELECTUAL À SOCIAL}

RESUMO: O artigo tem objetivo de expor uma investigação realizada sobre os vínculos históricopedagógicos de Paulo Freire com a Revolução Cubana. Se utiliza uma metodologia qualitativa para precisar em tempo, espaço e transcendência das relações do objeto de estudo. Avaliam-se os contextos de partida, o interessante mosaico de circunstancias internacionais e nacionais em que se moveram tais relações, as raízes das lutas emancipatórias caribenhas, latinoamericanas e mundiais da épica, e o impacto do protagonismo histórico de Freire e da Revolução Cubana, suas identidades, paralelos e confluências.

Palavras-Chave: Freire; educação popular e Revolução Cubana.

\footnotetext{
${ }^{1}$ Doctor en Ciencias Pedagógicas por la Universidad de Ciencias Pedagógicas “Enrique José Varona” (UCPEJV). Profesor Titular del Centro de Estudios Educacionales de la UCPEJV. Investigador Titular y Jefe del Proyecto "EI conocimiento histórico pedagógico en la enseñanza de la Historia de Cuba y América", proyecto asociado al Programa Nacional de Ciencias del Ministerio de Ciencia, Tecnología y Medio Ambiente de la República de Cuba. E. mail: felipe@cubarte.cult.cu
} 


\section{PAULO FREIRE AND THE CUBAN REVOLUTION. 1959-1997: FROM THE INTELLECTUAL HISTORY TO THE SOCIAL ONE}

ABSTRACT: The aim of this article is to expose the research made on the historical-pedagogical ties of Paulo Freire with the Cuban Revolution. A qualitative methodology is used to precise in time, space and transcendence, the study object relationships. The contexts of the starting point, the interesting mosaic of international and national circumstances in which these relations have moved, the roots of the fight for freedom in the Caribbean, in Latin American and in the world, and the impact of the historical leading role of Freire and of the Cuban Revolution, the identities, parallels and confluences.

Key words: Freire, popular education, Cuban Revolution

\section{INTRODUCCIÓN}

Paulo Reglus Neves Freire (1921-1997) fue un latinoamericano de la época que marcó para el continente, el triunfo en Cuba de la primera revolución socialista del hemisferio occidental. Época en que, junto con un auge de los movimientos liberadores, se concreta -al decir de Carlos Alberto Torres (1996)-, un nuevo horizonte intelectual para la región.

Como la mayoría de las personas de su generación Paulo Freire sintió siempre una profunda simpatía por la Revolución Cubana. A Rosa María Torres (1997) le confesaría: "Yo tengo una pasión especial por Cuba". Estaría además muy ligado con el país caribeño, por el hecho de que su primera esposa Elza Maia Costa de Oliveira (1916-1986),"su educadora...su amante y profesora de sus hijos" como gustaba referirse, "amaba a Cuba" (Freire, 1997, p 14).Freire definirá a Ernesto Che Guevara de la Serna (1928-1967) y Fidel Castro Ruz (19262016) con la categoría de "pedagogos de la revolución" (Freire, Pérez, y Martínez, 1997, p 20). La simpatía de Freire con la Revolución Cubana, su identidad en principios pedagógicos y revolucionarios, paradójicamente no ha coincidido con el más fluido acercamiento de los pedagogos, maestros y maestras cubanos a la obra freiriana. Rosa María Torres testimonia que a inicios de la década de 1980, cuando llegó a Cuba en visita de estudio, Freire no era un autor apreciado sino más bien duramente criticado por los educadores cubanos y sus libros no 
eran conocidos en la isla (Torres, 1997). Similar criterio aporta Carlos Alberto Libânio Christo, Frei Betto (2007a, 2007b). El autor estudiante de pedagogía y maestro en las décadas del setenta y principios de los ochenta, coincide con los criterios de ambos testimoniantes. Desde entonces, en las cuatro décadas transcurridas, ha crecido en el país el conocimiento y el activismo pedagógico de inspiración freiriana, pero aún su obra no se aprecia ni aporta en toda su magnitud.

En tanto tema para aprendizajes que sumen lo mejor de la práctica y la teoría pedagógica caribeña y latinoamericana, al esfuerzo de perfeccionamiento del socialismo cubano, el estudio de la relación Freire-Cuba abre un interesante campo para las investigaciones pedagógicas, históricas y politológicas. En este artículo pretendo sintetizar el acercamiento que hemos realizado.

\section{IDENTIDADES}

El movimiento de educación popular que liderado por Paulo Freire renace en la Latinoamérica y el Caribe de finales del Siglo XX, comparte nutricias y profundas raíces con el que más tempranamente se articuló en Cuba. En conexión con América Latina y el Caribe, es sostenida la presencia de núcleos teóricos y prácticos reconocidos como educación popular, que están presentes en Argentina, Brasil, Perú Colombia, Venezuela, México, y en la experiencia de otros pueblos del continente. En la Mayor de las Antillas es consensual considerar "popular" toda la educación adoptada por la Revolución que triunfa el 1ro. de enero de 1959, definida como tal por los padres fundadores de la escuela cubana a principios del Siglo XIX, en primer lugar, por el sacerdote revolucionario Félix Varela Morales (1788-1853), y definitivamente con la extraordinaria impronta de José Martí Pérez (1853-1895), Héroe Nacional cubano, y uno de los pensadores y pedagogos imprescindibles en la historia de las ideas, la cultura y la educación del Siglo XIX americano. Martí es considerado el autor intelectual de la actual Revolución Cubana. 
Lo particular en cuanto a la categoría educación popular, que caracteriza la historia educacional cubana ha sido precisado Frei Betto (2010): “Para hacer justicia con la historia, el primero que practicó educación popular fue José Martí. Martí decía que había que llevar los maestros a los campos. Y con ellos, la ternura que hace falta a los hombres". "Para Martí, precisa el dominico brasileño, lo "popular" no lo era en el sentido de pobre, sino de pueblo".

Freire reconoció reiteradamente entre sus fuentes nutricias a José Martí. Una vez le preguntaron si él se había inspirado en Martí y dijo que todo el que lee a Martí se queda inspirado y llega de alguna manera a interiorizarlo (Miguens Lado, 2007). Es que como plantea Miguel Alvarado Arias (2007), las ideas sobre educación de Martí y Freire responden a una concepción de mundo en la que la reflexión y la acción se insertan en una praxis que los ubica como intelectuales contra hegemónicos, al estilo de lo que Gramsci (1967) concibió como intelectuales orgánicos. Tanto uno como otro se plantearon una ruptura epistemológica y ontológica del paradigma egocéntrico y antropocéntrico de la cultura occidental: Lo que para Danilo R. Streck (2017) resulta en las coincidencias de libertades en relación a la ruptura de cánones cerrados y la pertinencia de pensar la experiencia de vida y la práctica.

La educación popular en Cuba fue eminentemente política, pues estuvo en el centro de los proyectos nacional liberadores de matriz anticolonialista primero, y antimperialista y socialista después. Prácticamente se puede establecer un eje ideológico cultural de continuidad histórica, entre los movimientos educacionales de las etapas colonial y neocolonial, que definitivamente se rescatan, redefinen y multiplican en realizaciones, con los movimientos político culturales de resistencia, lucha y emancipación, y la obra de la Revolución después de 1959 (Pérez, 2009).

\section{PRIMERAS NOTICIAS}

A Freire le llegan las primeras noticias de la Revolución Cubana, cuando trabaja en Recife con el Movimiento de Cultura Popular (MCP) ${ }^{2}$. Entonces Germano Coelho, presidente

\footnotetext{
2 El MCP fue creado en mayo de 1960 (Rodríguez, 2015, p 64).
} 
de ese movimiento fue invitado a visitar Cuba, y regresó con los materiales metodológicos y didácticos de la Campaña Nacional de Alfabetización realizada en Cuba en1961, exactamente en el momento en que él y sus compañeros hacían una búsqueda de algo que no fueran las tradicionales cartillas para niños, usadas también para adultos (Góes, 1995).

Los educadores brasileños querían alfabetizar al pueblo como misión política, y asumen la categoría que en español pudiéramos entender como "concientización", y para tal fin, la cartilla cubana les fue una revelación. "Encontramos en la Cartilla de Cuba -afirma Josina Thales (2008)-, lo que no había en otras cartillas - lo que llamaríamos "palabras-clave", (más tarde Paulo Freire les dio el nombre de "palabras-generadoras"), alrededor de las cuales se desarrollarían los asuntos que considerábamos importantes para la concientizaciónpolitización de la población". En aplicación de lo que habían investigado, crean su propia cartilla, titulada Livro de Leitura de Adultos, inspirada en la cartilla cubana Venceremos.

Freire no comparte el método cubano y está en desacuerdo con la utilización Livro de Leitura de Adultos. Propone una enseñanza con base en textos populares. En su criterio los eslóganes producirían siempre efectos domesticadores, tanto a la derecha como a la izquierda (Biesiegel, 1998). No podía conocer entonces el pedagogo pernambucano que en las batallas de clase de 1959 y 1960, se crearon en Cuba las premisas sociopolíticas y las precondiciones objetivas, para el despliegue de un gran movimiento educacional de masas, capaz de asumir las demandas de la democratización de educación, la práctica pedagógica, los maestros y de sus potenciales alumnos, como proceso cultural y en tanto lucha política e ideológica por la hegemonía de los valores del humanismo socialista y la justicia social. Precisamente la planificación y ejecución de la Campaña Nacional de Alfabetización fue momento culminante de tal movimiento educacional de masas (Pérez, 2001). Se considera que este disenso motivó el alejamiento de Freire del MCP (Rodríguez, 2015, p 66).

Cuando Freire se aprestaba a liderar la educación de adultos en Brasil, con el apoyo del Presidente João Goulart (1918-1976), el Golpe de Estado de 1964, interrumpe su labor. En aquel momento se encontraba en la Secretaría de Educación en Rio de Janeiro, y preparaba grupos para el empleo del método que ya había creado, y al mismo tiempo utilizaba cartillas 
en otras provincias, donde no existían coordinadores con capacidad de usar el método dialógico.

El golpe de Estado, patrocinado por los Estados Unidos, fracturó el curso democrático de país del Cono Sur, e instauró una dictadura militar pro fascista que condujo a Freire y a cientos de educadores y hombres progresistas, a la cárcel primero, y el exilio después. Aún se desconoce la cifra de los patriotas brasileños que fueron torturados y asesinados (Dallari, 2015).

\section{FREIRE EN SUS CIRCUNSTANCIAS}

Freire nace a la actuación político educacional, en un contexto de incomunicación tanto en su país, como en el seno del movimiento progresista y revolucionario internacional, entre los partidos comunistas de orientación soviética, y la intelectualidad revolucionaria de formación cristiana.

La descomunal campaña anticomunista y antisoviética que orquestaban los gobiernos capitalistas, y las jerarquías de la Iglesia católica y de la mayoría de las Iglesias e instituciones religiosas a escala planetaria, había logrado enquistar en las sociedades de la época más que ideas, prejuicios contra los comunistas. La concepción vanguardista, y pensamiento "ateísta" predominante en la izquierda comunista de entonces dio su aporte "teórico" al desencuentro.

Frei Betto -activo participante en la izquierda católica desde los años sesenta-, recuerda como desde su primera obra importante "Educación como práctica de la libertad" (1967), Freire mereció de parte de intelectuales del Partido Comunista Brasileño la calificación de "idealista hegeliano" (Frei Betto, 2007).

Los temas de la explotación y del poder político, no quedaron -ni ello se lo había propuesto el autor-, suficientemente esclarecidos en la denuncia que bajo el concepto opresión propone Freire en Pedagogía del oprimido, título de 1969. Su óptica se dirige definitivamente al mundo de las sensibilidades, la psicología, y la vida espiritual de los sujetos, temas entonces subvalorados por el llamado marxismo-leninismo de fuerte matriz dogmática. En ocasión de ser publicado en Brasil, su libro "Pedagogía de la Esperanza. Un reencuentro con 
la Pedagogía del Oprimido", (1992) Freire ese refirió a las críticas que 24 años antes había recibido: "...las críticas marxistas eran casi todas mecanicistas. La mayoría de ellas, con excepciones, claro, se fundamentaban en una comprensión mecanicista de la historia. Eran críticas marxistas y por lo tanto proclamativas de la concepción dialéctica; pero eran profundamente no dialécticas" (Claudia Korol, 1993).

La distancia, además, no solo era de orden filosófico. Ni querían, ni podían entender los comunistas brasileños de entonces, el hecho de que aquel intelectual pernambucano había creado un método de alfabetización, que facilitaba el diálogo entre la izquierda y los pobres, menos podían asumir que estaban ante una pedagogía pensada para la emancipación, para la crítica a la oligarquía y el capitalismo. Esta posición les impidió a los comunistas brasileños y a la intelectualidad de los partidos que le eran afines, penetrar en la esencia político revolucionaria del planteo pedagógico freiriano, y en los años que le sucedieron les mantuvo alejados de la evolución de su pensamiento.

Freire por su parte -puede entenderse-, no parece haber tenido ningún acercamiento sustancial con la izquierda comunista brasileña de entonces. El Freire del Brasil de los años sesenta, era en lo fundamental un pedagogo revolucionario ocupado por el ansia de llevar adelante su propuesta. Exigirle la madurez y la agudeza política que luego alcanzó, resulta un ejercicio sumamente errático. No dejará de reconocer Freire como algunas de sus decisiones -tal es el caso de aceptar un financiamiento de la derecha de Rio Grande do Norte para alfabetizar en ese estado-fueron cuestionadas, incluso por sus amigos cercanos (Rodríguez, 5, p 6).

En los años exilio político, los juicios sobre Freire en los círculos de la izquierda comunista, continuaron afectados. La vida del pedagogo centrada en el trabajo académico, transcurrió por derroteros que para sus críticos, ratificaban el perfil de un intelectual reformista y pro burgués, en tiempos en que el movimiento revolucionario era golpeado por engendros de asesinato político transnacional como el Plan Cóndor, las persecuciones, el espionaje y la promoción del divisionismo. 
Del exilio chileno lo que afloraba para reafirmar la tesis de su alineación reformista, era la relación con el gobierno demócrata-cristiano de Eduardo Frei, a lo que sumaba la beca que cursó de diez meses en la Universidad de Harvard. Luego, a partir de 1970 fue funcionario en Ginebra del Departamento de Educación del Consejo Mundial de las Iglesias, organismo que por entonces era apreciado por los servicios de inteligencia soviéticos y del campo socialista, como una posible fachada de las agencias enemigas, de la estadounidense Agencia Central de Inteligencia $(\mathrm{ClA})$ y los servicios similares de la militarista Organización del Tratado del Atlántico Norte (OTAN).

Sin dudas el acercamiento temprano, físico y propositivo, entre Freire y la Revolución Cubana, fue afectado por esa ríspida relación con el movimiento comunista. Frei Betto testimonia como dialogó con dirigentes de países socialistas, de la Unión de Repúblicas Socialistas Soviéticas (URSS), y pudo apreciar un gran prejuicio contra Paulo Freire (Frei Betto, 2007).

\section{CON RAÚL FERRER}

Para entender las relaciones de Paulo Freire con la pedagogía cubana se hace imprescindible estudiar el inédito camino de sus encuentros con Raúl Ferrer Pérez (1915-1993) y con otros educadores cubanos. Freire conoció a Ferrer en Paris en 1965, de paso ambos para asistir a la Conferencia Mundial contra el Analfabetismo de Teherán, también conocida como Congreso Mundial de Ministros de Educación sobre la Erradicación del Analfabetismo (Ferrer, 1988, p VII).

Ferrer había sido un destacado líder magisterial afiliado al primer partido comunista de Cuba, y al triunfo de la Revolución fue invitado por Armando Hart Dávalos (1930-2017), primer ministro de educación del nuevo poder popular, junto a otros destacados pedagogos de diferentes corrientes filosóficas y militancias políticas, a integrase a la tarea de revolucionar la educación, y resolver los graves problemas acumulados tras siglos de herencia colonial y neocolonial. Este maestro sería el artífice pedagógico de la Campaña Nacional de 
Alfabetización, y después máximo impulsor de la educación de adultos en el país (Freire, 1976, Pérez, 2001, p 109). Del privilegiado testimonio de Ferrer, Freire quedó profundamente emocionado con aquella hazaña realizada por los cubanos de alfabetizar a más de 900 mil personas en menos de un año. Para Paulo Freire "la campaña de Alfabetización de Cuba, seguida años después por la de Nicaragua, constituyen uno de los más importantes hechos de la historia de la educación en el Siglo XX" (Freire, 1997, p 15).

Ferrer y Freire están en el Congreso de Teherán entre los que se destacan en la critican al entonces predominante concepto de la alfabetización como acción de aprendizaje de destrezas básicas. Ambos pedagogos apoyan la propuesta de "alfabetización funcional" y con ello marcan un hito importante en la historia moderna de la educación, al subrayar la alianza entre la educación - particularmente la alfabetización- con el desarrollo socioeconómico de los pueblos.

En sus labores como viceministro a cargo de la educación de adultos, Ferrer mantuvo un frecuente contacto con Freire. Ambos coinciden en lo limitado del Programa Experimental de Alfabetización Mundial (Simposio Internacional sobre Alfabetización, Persépolis, 1975) y trabajan por avanzar la integralidad de los conceptos de educación y alfabetización, al enfatizar las conexiones existentes entre la alfabetización y el protagonismo político dirigido a las transformaciones socioeconómicas. En estos años más allá de sus encuentros con Raúl Ferrer, no se registra otra relación de interés de Freire con la Revolución Cubana.

Freire y Ferrer volverían a encontrarse catorce años después, en 1979, en Nicaragua, en el escenario de la Revolución Sandinista, en la que ambos jugaron un importante papel en la asesoría de la Cruzada Nacional de Alfabetización "Héroes y Mártires por la Liberación de Nicaragua" (CNA). Fue intensa y significativa la cooperación que, con el liderazgo de ambos maestros, se estableció entre los equipos de especialistas cubanos y brasileños convocados por los organizadores nicaragüenses.

En vísperas de la visita de Freire a Cuba en 1987, Ferrer impulsó uno de los primeros círculos de estudio del pensamiento freiriano en Cuba, actividad para la que solicitó el apoyo de la educadora brasileña Josina Thales (Thales, 2008). La amistad de Freire y Ferrer marcó una 
continua relación de fraternidad e identidad entre ambos pedagogos revolucionarios. Ferrer y Freire dejaron pendiente un libro que habían acordado hacer (Canfux, 2005).

\section{LAS CIRCUNSTANCIAS CUBANAS}

En los años sesenta y setenta en el plano cultural y educacional, se desenvuelve una contradictoria situación nacional. Se trata de un momento particular sobre el que hay que hacer desde dentro de Cuba, una reflexión colectiva que solo recién comienza. A saber, a la par de los gigantescos y revolucionarios cambios que masifican y democratizan la educación y la cultura para millones de cubanas y cubanos, se desenvuelve una peculiar lucha ideológica y política - tanto en el sector artístico como en el académico, a nivel ideológico y cultural-, entre quienes imponían las concepciones fabricadas en la oficialidad partidista soviética, y no pocos compañeros y colectivos que las resistían sin abandonar los posicionamientos revolucionarios. En los años sesenta y setenta del pasado siglo, la Pedagogía y la escuela cubanas estaban en pleno proceso de cambio de paradigmas. La tradición de una escuela nacional humanista, democrática y científica, para asumir definitivamente los rasgos y el contenido popular y socialista, tuvo necesariamente que desembarazarse de los lastres academicistas y profesionalizantes, que predominaban en las colectivos y directivas del Colegio de Pedagogos, en la Escuela de Pedagogía de la Universidad de La Habana, y en otros espacios magisteriales. Una nueva intelectualidad profesoral comenzó a formarse en los planes masivos de formación de maestras y maestros y en la gran escuela de pedagogía revolucionaria que fue el movimiento educacional de masas de la alfabetización, en las campañas sucesivas de la post alfabetización, para elevar el nivel de instrucción y cultura de los trabajadores y campesinos, los planes de becas y las primeras medidas de universalización de la universidad.

El desarrollo científico técnico alcanzado por la URSS y alto nivel teórico metodológico de la pedagogía y la didáctica soviéticas -y de otros países socialistas europeos como la República Democrática Alemana-, junto con las inmensas facilidades otorgadas para la capacitación y asesoría del personal cubano dentro y fuera del país, fueron determinantes para 
la modernización y el desarrollo científico de la escuela y la universidad cubanas. La masificación y consolidación del paradigma marxista, en el más amplio universo educacional cultural cumplió la tarea de garantizar la hegemonía ideológico cultural socialista, pero nos contaminó con los enfoques escolásticos del marxismo-leninismo.

La escuela cubana en esos años no pudo sacudirse del exceso de normatividad e institucionalidad, así como de los enfoques que eludían la historia de la educación nacional, y subvaloraban las ideas pedagógicas de la tradición cubana, a favor de la teorización mecanicista en curso, de los autores y los manuales soviéticos. El núcleo de pedagogos de vanguardia que el ministro Hart consolidó en los momentos del despegue de la Revolución educacional, fue paulatinamente sustituido por cuadros afines a las concepciones soviéticas, y por los nuevos especialistas formados en tal ambiente. El ministro Hart es designado para otras importantes tareas partidistas.

Si hasta el estudio de José Martí sufrió a causa de la situación descrita, menos aún serian propicias las circunstancias para una apertura a Freire. La inconexión del pensamiento educacional cubano con Freire, no sería ajena a la voluntad de dogma que prevalecía. El desconocimiento de la literatura freiriana en estas primeras décadas fue resultado también de la pérdida de contacto efectivo con el movimiento pedagógico latinoamericano, con las escuelas, las universidades y las maestras y maestros; en medio del cerco agresivo del bloqueo impuesto por Estados Unidos a través de la Organización de Estados Americanos (OEA), a las relaciones de Cuba con los gobiernos burgueses de la región (Canfux, 2007).

El cúmulo de factores que refiero, completan la explicación, del por qué durante las dos primeras décadas de la Revolución Cubana, no existieron contactos directos con Freire.

\section{EN LOS ESCENARIOS DE LUCHAS}

Si bien el extraordinario apoyo que la URSS brindó para la sobrevivencia de la Revolución, y la justa admiración y respeto que creció en Cuba por la Unión Soviética, tuvo su consecuencia en espacio para que se introdujeran gran parte de los presupuestos del 
marxismo-leninismo y del llamado "socialismo real", ello no fue suficiente para minar la tradición de autoctonía, el espíritu soberano de los revolucionarios cubanos. El Partido Comunista de Cuba, con el liderazgo de Fidel Castro -acompañado por Che Guevara y otros miembros de la dirección revolucionaria-, mantuvo dentro del seno del movimiento comunista internacional, una sostenida postura de independencia política y criticidad martiana y marxista, que a la postre resultaría decisiva. Esta postura fue muy significativa en la defensa del histórico compromiso internacionalista y latinoamericanista de la Revolución.

En franco desacuerdo con los criterios del Partido Comunista de la Unión Soviética, Cuba asumió sus deberes para con la lucha antimperialista a nivel latinoamericano y mundial. El apoyo al movimiento guerrillero, y a las fuerzas y organizaciones que resistían a las dictaduras militares, la Conferencia Tricontinental (1966) y la creación de la Organización de Solidaridad con Asia. África y América Latina (OSPAAAL) y de la Organización Latinoamericana de Solidaridad (OLAS) (1967), se constituyeron en hechos trascendentes que fracturaron en buena medida las relaciones con varios Partidos Comunistas latinoamericanos que sostenía acríticamente los criterios soviéticos (Pérez 2008).

La opción de los revolucionarios cubanos, los acercó a la izquierda marxista que había salido de los partidos que no coincidían con las tesis de la lucha armada. Y por supuesto también se establecieron sólidas relaciones de colaboración con la militancia de la izquierda cristiana. En este camino llegaron a Cuba los primeros textos de la Teología de la Liberación, y se conoció y apreció la labor de las comunidades eclesiales de base, y por supuesto a Paulo Freire y el movimiento de los educadores populares.

Las derrotas de las organizaciones y movimientos revolucionarios armados en la región, y el Golpe de Estado y asesinato de Salvador Allende en 1973, marcan un punto de inflexión. Y ello imponen junto con un reflujo general de las luchas guerrilleras, la búsqueda de nuevas formas y escenarios, para dar continuidad a la resistencia popular, sin renunciar al enfrentamiento anticapitalista y antimperialista. En la propuesta pedagógica, los activistas revolucionarios, encuentran nuevas maneras de trabajar con las masas, con una perspectiva 
que -como subraya el mexicano Carlos Núñez Hurtado (1942-2008), - no era de derrota, sino de resistencia, (Núñez, 2003).

En los escenarios de las luchas nacional liberadoras del continente, comenzó a fracturarse para los cubanos, el desconocimiento y las dudas sobre Paulo Freire y la educación popular. Quienes accedimos entonces a Freire, no logramos aún comprender toda la magnitud de su propuesta. Solo asumimos el movimiento de educación popular en lo que ello significaba para la lucha revolucionaria en el escenario regional, sin proponernos estudiar, conocer y evaluar sus aportes para el desarrollo de nuestro propio proyecto educacional. Este conocimiento, no llegó a ser un saber compartido y socializado, se circunscribió a quienes por razones del trabajo internacional y solidario que realizaban, mantenían más estrechas relaciones con la región latinoamericana, pero sentó las bases para el inevitable encuentro.

\section{CON LOS MISMOS PROTAGONISTAS}

Funcionario de educación del Consejo Mundial de Iglesias, Paulo Freire se desempeñó como asesor para los países del llamado Tercer Mundo. Viaja por primera vez al continente africano y visita Tanzania y Zambia, y de inmediato lo contactan las direcciones del Movimiento para la Liberación de Angola (MPLA), el Frente de Liberación de Mozambique (FRELIMO) y el Partido para la Independencia de Guinea Bissau y Cabo Verde (PAIGC) (Freire, Macedo,1987, p 94). Sorprendió a Freire el conocimiento que tenían de su obra, los patriotas africanos que enfrentaban el colonialismo portugués. Y el pedagogo brasileño no duda en comprometerse con su causa.

Entre 1975 y 1980, Freire trabajó en Guinea Bissau, Santo Tomé y Príncipe, Mozambique y Angola. En Guinea Bissau, asesoró los esfuerzos de alfabetización y la educación de adultos que emprendió el PAIGC en los territorios liberados primero, y con la independencia 
después ${ }^{3}$. (Freire, Paulo: 1977). Dejó constancia de la campaña de alfabetización realizada en este país, en Cartas a Guinea-Bissau (1977). También Sao Tomé y Príncipe, tras su liberación del colonialismo portugués ${ }^{4}$, encargó a Freire un programa destinado a fomentar la alfabetización.

El contacto con los combatientes anticolonialistas africanos y sus más destacados líderes políticos, Julius Kambarage Nyerere (1922-1999), Samora Moisés Machel (1933-1986), António Agostinho Neto (1922-1979) y Amílcar Lopes da Costa Cabral (1924-1973), fue una experiencia trascendental para el pedagogo brasileño (Freire, Guimarães, 2003). De manera particular se inscribe la amistad que llegó a estrechar con Cabral, intelectual nacionalista de sólida formación marxista (Gadotti, 1997). La experiencia africana dinamiza en Freire nuevas profundizaciones teórico filosóficas (Mac Laren, 2000). En África y con los africanos Freire arriba a la universalidad como intelectual, pedagogo y patriota internacionalista.

No casualmente en el escenario africano que Freire transitaba, coincidió con los internacionalistas cubanos, que habían retornado a la tierra de sus abuelos africanos, para contribuir a la liberación nacional y el desarrollo de sus pueblos. Trescientos ochenta y un mil cubanos y cubanas, fueron al continente africano, de manera voluntaria, para combatir por la independencia de las naciones de sus ancestros esclavos. Ciento veinte mil más, lo han hecho hasta la actualidad en calidad de colaboradores civiles, con servicios solidarios donde el magisterio y la salud han sido las actividades más privilegiados (Pérez, 2008).

A solicitud de los revolucionarios congoleses, en abril de 1965 un primer contingente de combatientes internacionalistas cubanos, liderados por el Che Guevara, se internó en la selva del Congo Leopoldville (hoy República Democrática del Congo), y comenzó así la epopeya africana de la Revolución Cubana. La colaboración se dirigió inicialmente a la preparación de especialistas y cuadros dirigentes, el envío de instructores militares, médicos y ayuda material.

\footnotetext{
${ }^{3}$ EI PAIGC poseía el control de muchas partes de Guinea, y la independencia fue declarada unilateralmente el 24 de septiembre de 1973. El reconocimiento se hizo universal después del golpe militar en Portugal de abril de 1974, que derrocó a la dictadura del Ilamado Estado Novo. (1926-1974).

${ }^{4}$ La República Democrática de Santo Tomé y Príncipe obtuvo su independencia de Portugal el 12 de julio de 1975.
} 
Cuando la patria de Amilcar Cabral logró la independencia, cerca de sesenta internacionalistas cubanos, entre ellos una decena de médicos, llevaban diez años junto a las guerrillas del PAIGC.

Los combatientes internacionalistas cubanos acudieron en 1975 a la defensa de la recién independizada República Popular de Angola, invadida por tropas sudafricanas y zairenses (del régimen de Mobuto Sese Seko, (1930-1997), y subvertida por destacamentos de mercenarios y fuerzas contrarrevolucionarias angolanas, pagadas por Sudáfrica y la Agencia Central de Inteligencia (CIA) de los Estados Unidos. En febrero de 1976 llegó a Angola el primer grupo de asesores cubanos de educación, que luego se multiplicaría en miles de jóvenes maestros del Contingente Pedagógico Internacionalista Ernesto Che Guevara. El Contingente integrado por estudiantes de las carreras pedagógicas, trabajaron en la alfabetización, en la educación media y parte de la primaria. Según Neiva Moreira, y Beatriz Bissio (1979) los jóvenes del Contingente "Che" Guevara atendieron una población de 30000 niños y jóvenes angolanos.

No existe en la historia de la educación mundial una acción más masiva y multilateral de colaboración educacional, como que la que Cuba desarrolló en Angola, que además se realizó en un país en guerra, con los educadores constantemente agredidos por las fuerzas contrarrevolucionarias y los invasores sudafricanos.

La labor africana de Paulo Freire le permitió conocer el aporte internacionalista de la Revolución Cubana, muchos de sus amigos africanos, en particular Cabral y Nyerere eran entrañables hermanos de lucha de los revolucionarios cubanos, del Che Guevara y Fidel Castro. Del testimonio directo de Cabral tendrá el pedagogo brasileño inéditos testimonios sobre el Che Guevara.

En junio-julio de 1976 se produce el histórico encuentro de Paulo Freire con los educadores cubanos que estaba destacados en Angola. El pedagogo brasileño es invitado a visitar el país y dar sus opiniones sobre las acciones educacionales que desarrollaba la joven república angolana. En Luanda contacta con los asesores cubanos que cooperaban con el Ministerio de Educación angolano. 
Freire aprovechó su visita para estudiar en la práctica el método y la estrategia cubana de alfabetización. Como era de esperar se interesó particularmente por la cartilla para analfabetos, y el manual que los cubanos habían desarrollado, como principales instrumentos didácticos. Sus interlocutores le ratificaron la experiencia histórica cubana con tales instrumentos, y su validez para la realización de campañas masivas.

Conocedores de la propuesta de Freire, le explicaron que su método con la palabras generadoras precisaba de un maestro o activista con una relativa preparación cultural y educacional, y la necesidad de masificar los sujetos pedagógicos tanto en la experiencia de la Campaña cubana de 1961, como en la que entonces se desarrollaba en Angola, imponía darle la tarea de alfabetizadores a personas que si bien pudieran leer y escribir, no necesariamente rebasaran el bajo nivel educacional general heredado del depuesto sistema colonial. Freire quedó muy satisfecho con la explicación realizada por los asesores cubanos, y tuvo elogiosas palabras ante los anfitriones angolanos (Legón, 2005, Villasana, 2006).

Queda para la historia que aún nos falta por desbrozar, el hecho significativo de que, luego de su visita a Angola, en la asesoría que realiza en Sao Tomé y Príncipe, Freire propuso la utilización de una cartilla.

\section{NICARAGUA}

Tres años después del encuentro en África, Nicaragua, como ya lo señalamos, se constituye en lugar de privilegiado reencuentro de Freire con los pedagogos del archipiélago antillano. La Revolución Sandinista que triunfó el 19 de julio de 1979, asumió como una de sus más importantes tareas la erradicación del analfabetismo. En aquel momento el índice de analfabetismo en el país era superior al 50\%, uno de los mayores de América Latina, y para luchar contra tal flagelo se organizó la Cruzada Nacional de Alfabetización "Héroes y Mártires por la Liberación de Nicaragua" (CNA), dirigida el líder sandinista y sacerdote jesuita Fernando CardenalMartínez (1934-2016). A solicitud de las autoridades nicaragüenses, la Revolución Cubana acudió en ayuda solidaria del pueblo centroamericano, y 1200 de maestros integraron 
el Contingente Augusto César Sandino. Este contingente apoyó la alfabetización, la reorganización y expansión de la educación primaria, desde los barrios marginales hasta las más apartadas comunidades rurales.

Los revolucionarios nicaragüenses tenían una relación muy raigal con Paulo Freire, quien visitó en varias oportunidades el país, y contribuyó con sus ideas y con miembros de su equipo, a la asesoría de la CNA. Entre los asesores cubanos y los internacionalistas del equipo freiriano que trabajaron en el Ministerio de Educación sandinista, se estableció una fluida y muy rica relación profesional y personal (Canfux, 2005; Chávez, 2006; Pinto, 2007).

Los cubanos potenciaban la experiencia de la cartilla y el manual como principales instrumentos didácticos para la alfabetización, y este fue el camino metodológico seguido por la Cruzada Nacional de Alfabetización nicaragüense. Freire y sus seguidores, validaban el método de la acción participativa y el trabajo desde palabras generadoras. Las diferencias en método no produjeron tensiones, ni afectaron la mutua colaboración. Tanto en la perspectiva cubana como en la freiriana, el conocimiento no era un don que se entrega gratuitamente a quienes no sabían, sino que debía convertirse en un diálogo de saberes. Por lo tanto, el hecho educativo para ambos equipos se asumía como proceso de enseñanza y aprendizaje, formación de conciencia, rescate y desarrollo de la cultura popular, con base en el saber y el compromiso participativo de los sujetos - maestros, estudiantes y activistas-implicados en una relación pedagógica de carácter emancipatorio y de dignificación humana.

Como antes lo había sido en la Cuba de 1961, en Angola, y en otros pueblos africanos, el movimiento educacional de masas de la alfabetización nicaragüense, no tardó en ser considerado como objetivo "militar" por las bandas contrarrevolucionarias organizadas y pagadas por la $\mathrm{CIA}$. Contra los alfabetizadores sandinistas y los internacionalistas de Cuba y otros pueblos hermanos, se empleó a fondo la presión psicológica, los ataques terroristas y el asesinato político. Nueve maestros cubanos fueron asesinados. 


\section{LA VISITA DE FREIRE}

Después de los amplios contactos con los educadores cubanos en Angola y Nicaragua, la figura de Freire comenzó a ser conocida en el país. Y la primera literatura freiriana llegó a las universidades e institutos pedagógicos, como parte de la riqueza cultural con la que retornaban a la patria los maestros internacionalistas. La favorable situación que sobre Freire se configuró, tendrá por dinamizador el despegue en el país de una nueva etapa del proceso político revolucionario

Los contactos de Fidel Castro con los cristianos y teólogos revolucionarios latinoamericanos, y las reflexiones del líder de la Revolución Cubana sobre la validez teórica y práctica de la unidad estratégica entre cristianos y marxistas, se constituyeron en una peculiar condición para la promoción en Cuba de las ideas de Freire y del movimiento de la educación popular. Un papel sustantivo en esta historia lo tuvo Frei Betto, ya muy conocido en Cuba, por su libro de 1985 Fidel y la Religión.

Tengo que manifestar la gratitud a Fidel -testimonia Frei Betto- por el apoyo explícito a esta labor latinoamericana por la educación popular. Cuando a inicios de los años 80 en Brasil todavía vivíamos bajo la dictadura militar, nos invitó a hacer en La Habana el Primer Encuentro Latinoamericano de Educación Popular en el año de 1983. Después promovimos aquí un segundo encuentro en el año de 1986, y después un tercer encuentro en el año de 1990. Desde entonces muchos cubanos se han familiarizado con este trabajo de educación popular" (BETTO, 2007).

Los eventos de educación popular en la Casa de las Américas, la publicación de los documentos por la revista de la Casa, y la primera promoción a escala de las obras de Freire entre los cubanos, coinciden con momentos en que las tendencias dogmáticas han perdido su batalla en el seno de la política cultural cubana. Cuando además el socialismo cubano se sometía a una aguda reflexión autocrítica, y revisaba las consecuencias de las asunciones miméticas del modelo soviético. 
El proceso de rectificación de errores y tendencias negativas iniciado en 1985 y 1986, constituyó una revolución conceptual profunda. La crítica política y el reencuentro con los fundamentos más genuinos del nacionalismo, el marxismo y la ideología revolucionaria cubana, marcaron los momentos significativos de la autocrítica y reflexión colectiva a la que entonces convocó Fidel Castro. Las desviaciones economicistas y el deterioro de la conciencia revolucionaria, fueron los asuntos medulares colocados a debate y rectificación.

La rectificación fue al rescate y reafirmación, de las esencias más autóctonas de la cultura y la historia nacional. Este proceso se re-orientó en la recuperación del universo ideoteórico que proporciona José Martí. El legado del Héroe Nacional cubano entonces y ahora, resulta imprescindible, para entender la articulación del marxismo y el leninismo en la cultura cubana, y en tanto plantearse las imprescindibles continuidades y rupturas dialécticas que la Revolución precisa. En el plano escolar la rectificación condujo a la recuperación del proceso pedagógico, en su integralidad formativa, y a situar en su centro la reafirmación y construcción de valores humanistas y socialistas.

El proceso interno cubano en esos primeros a los de la década del ochenta, recibe la favorable circunstancia de la reapertura de relaciones con la mayoría de los gobiernos del área caribeña y latinoamericana. La ruptura de la política de cerco y bloqueo, reactivó el intercambio y la presencia del país antillano en los espacios culturales latinoamericanos.

En este clima de avances y búsquedas rectificadoras se produce en junio de 1987, la primera y única visita de Paulo Freire a Cuba. El destacado pedagogo llega a La Habana en oportunidad del XXI Congreso interamericano de Psicología ${ }^{5}$.Pudo escuchar una de las más medulares intervenciones de Fidel ante su pueblo, con el tema de la autocrítica de los errores cometidos en la construcción socialista y las vías de rectificación ${ }^{6}$. Se reunió con quienes en la Casa de las Américas trabajaban los temas del movimiento de educación popular, y también lo hizo con compañeros del Ministerio de Educación (Canfux, 2005; Chávez 2006).

\footnotetext{
${ }^{5}$ EI XXI Congreso Interamericano de Psicología se desarrolló entre el 29 de junio y el 3 de julio de 1987.

${ }^{6}$ La comparecencia de Fidel Castro en la televisión nacional se realizó el 24 de junio de 1987.
} 
Tardó el encuentro, pero el Freire que llega e intercambia con sus colegas del archipiélago, está en condiciones de entender y aportar a Cuba, en su más madura dimensión. Este es el Freire que se aprecia en una histórica entrevista que le tomaron en La Habana Esther Pérez y Fernando Martínez Heredia, en la que el pedagogo brasileño se extendió en consideraciones sobre la ideología revolucionaria y la pedagogía de la Revolución. Sobre Cuba fue enfático:

Estoy en un país -afirmó- en el que hay un horizonte de libertad, de creatividad, en que la Revolución tiene la valentía de decir que también se equivoca...que hay compañeros de la dirección revolucionaria que se equivocan. Esto para mí -y parece un absurdo casi mágico lo que voy a decires como si yo no pudiera partir del mundo sin conocer materialmente, palpablemente, sensiblemente, a Cuba. He depositado mi cuerpo en tu país, porque ya antes había depositado en él mi alma - sin dicotomizar una cosa de la otra, ¿̇eh?- (FREIRE, PÉREZ y MARTÍNEZ, 1997).

A Freire se le esperaba nuevamente en Cuba para mayo de 1997, iba en esta visita a ser objeto de un merecido reconocimiento tanto por la Universidad de La Habana, como por el Ministerio de Educación, y otras instituciones gubernamentales y sociales. Esta visita hubiera sido decisiva para el más amplio conocimiento de la obra de Freire en el país, pero desafortunadamente su desaparición física el 2 de mayo de 1997, la impidió.

\section{BIBLIOGRAFÍA}

ALVARADO ARIAS, M. José Martí y Paulo Freire: aproximaciones para una lectura de la pedagogía crítica, Revista electrónica de investigación educativa, REDIE. vol. 9 n.1. 2007

BIESIEGEL, C. de R. Paulo Freire y la Educación Popular en Brasil. Entrevista realizada por Jean Lauand. Faculdade de Educação da Universidade de São Paulo (FEUSP). San Pablo: 1998.

BETTO, F. Cuba: Educación y Neocolonialismo, Adital, 2007. Disponible online: http://www.adital.org.br) (Última consulta: diciembre del 2019).

BETTO, F. Cuba y Paulo Freire, Red en defensa de la humanidad, 7 de mayo del 2007. Disponible online: http://www.defensahumanidad.cult.cu. (Última consulta: diciembre del 2019). 
BETTO, F. La Revolución Cubana se mueve críticamente sobre sí misma. Versión de las palabras pronunciadas por Frei Betto en el contexto del IV Encuentro Nacional de educadoras y educadores populares, en La Habana, el 10 de noviembre de 2010. Cubadebate. Disponible online:www.cubadebate.cu > opinion > (Última consulta: diciembre del 2019).

CANFUX GUTIERREZ, J. Hacia una escuela cubana de alfabetización. La Habana: Editorial Pueblo y Educación, 2007.

DALLARI, P. B. A. La Comisión Nacional de la Verdad de Brasil: algunas notas sobre su trabajo, informe final, conclusiones y recomendaciones con un enfoque en el sistema de justicia. Sistemas Judiciales. Ano 15, n.19, 2015. p.46-54.

FERRER, R. Educación de adultos en Cuba. La Habana: Ministerio de Educación, 1976.

FERRER, R. Prólogo. En: PÉREZ, F. Las coordenadas de la alfabetización. La Habana, Editorial de Ciencias Sociales, 1988.

FREIRE, P. Educação e Atualidade Brasileira. Tese de Concurso para a Cadeira de História e Educação - Escola de Belas Artes de Pernambuco. Recife: 1959. Disponible online: http://acervo.paulofreire.org:80/xmlui/handle/7891/1976. (Última consulta: diciembre del 2019).

FREIRE, P. Alfabetização e conscientização. Porto Alegre: Editora Emma,, 1963.

FREIRE, P. Educação como prática da liberdade. Rio de Janeiro: Paz e Terra, 1967.

FREIRE, P. Pedagogía do oprimido. Rio de Janeiro: Paz e Terra, 1969.

FREIRE, P. Cartas a Guinea-Bissau. México: Siglo XXI, 1977.

FREIRE, P. Pedagogia da Esperança: um reencontró com a pedagogia do oprimido. Rio de Janeiro: Paz e Terra, 1992.

FREIRE, P. Pedagogia da autonomía. Saberes necessários à prática educativa. Rio de Janeiro: Paz e Terra, 1997.

FREIRE, P. Pedagogía de la esperanza. México: Siglo XXI, 1999.

FREIRE, P. BRANDÃO, C. R. Brandão y Betto, F. Palabras desde Brasil, Colección de Educación Popular. La Habana: Editorial Caminos, 1996.

FREIRE, P. y MACEDO, D. Literacy: reading the word and the world. Massachuset: Bergin \& Garvey, 1987. 
FREIRE, P. PEREZ, E. Y MARTINEZ, F. Diálogos con Paulo Freire, Colección de Educación Popular. La Habana: Editorial Caminos.1997.

FREIRE, P. y GUIMARÃES, S. A África ensinando a gente. São Paulo: Paz e Terra, 2003.

GADOTTI, M. A voz do biógrafo brasileiro: A prática à alturado sonho. Revista da FAEEBA. Salvador: V.6, jan/jun, 1997. p. 33-67.

GÓES, M: Cuba, Recife, Natal ou o sonho de trêscartilhas de alfabetização para mudar o mundo. Contexto e Educação. Revista de Educación en América y el Caribe. Sao Paulo: jul/set, 1995. p. 45-64.

GRAMSCI, A. La formación de los intelectuales. México: Grijalbo, 1967.

HANECKER, M. El sueño era posible. La Habana Editora Popular, 1994.

KOROL, C. Como nunca en la historia, Marx pagaría para vivir en el mundo de hoy. Entrevista al pedagogo brasileño Paulo Freire, 1993. Disponible online:http://www.pvp.org.uy. (Última consulta: diciembre del 2019).

LADO, M. La pedagogía de la revolución. Entrevista a la presidenta de la Asociación de Pedagogos de Cuba. Nydia González(I), Insurgente, mayo, 2007. Disponible online:http://www.insurgente.org). (Última consulta: diciembre del 2019).

LÓPEZ BLANC, H. Cuba: Puqueño gigante contra el aparteid, La Habana. Casa Editora Abril, 2008.

MACLAREN, P. Che Guevara, Paulo Freire, and the pedagogy of revolution. Lanham: Rowman\&Littlefield Publishers, 2000.

MOREIRA, N. y BISSIO, B. Os cubanos na África. São Paulo: Global Editora, 1979.

NúÑEZ, C. Pedagogía del Oprimido: "La educación verdadera es la que construye ciudadanía crítica. Página 12. México: 26 de noviembre del 2003.

PÉREZ, E. América Libre. Argentina: No. 18, Causas y azares. s/d. Disponible online:http://www.nodo50.org/americalibre (Última consulta: diciembre del 2019).

PÉREZ, E. Freire entre nosotros. Una experiencia cubana de educación popular. La Habana: Editorial Caminos, 2004.

PÉREZ CRUZ, F. de J. Las coordenadas de la alfabetización. La Habana: Editorial de Ciencias Sociales, 1988. 
PÉREZ CRUZ, F. de J. La alfabetización en Cuba: Lectura histórica para pensar el presente. La Habana: Editorial de Ciencias Sociales, 2001.

PÉREZ CRUZ, F. de J. El orden del desorden. La "revolución neoliberal en Brasil. La Habana: Ediciones CEA, 2006.

PÉREZ CRUZ, F. de J. Cuba: Solidaridad e internacionalismo socialistas. México: Contexto Latinoamericano, 2008.

PÉREZ CRUZ, F. de J. La educación y la pedagogía cubanas en el movimiento nacional liberador. Una visión panorámica de las revoluciones en los Siglos XIX-XXI. En: RAJLAN, B. y COTARELLO, M.C. (Comp.) La Revolución en el Bicentenario. Reflexiones sobre emancipación, clases y grupos subalternos. Buenos Aires: CLACSO, 2009.

RELYS DÍAZ, L.I. De América Soy hijo...Crónica de una década de alfabetización audiovisual. Girona: La Guerrilla Comunicacional, 2013.

RODRÍGUEZ, L. M. Paulo Freire. Una biografía intelectual. Surgimiento y maduración de la pedagogía del oprimido. Buenos Aires: Ediciones Colihiue, 2015.

ROMO TORRES, R. Contribuciones Freirianas al pensamiento latinoamericano. En: GADOTTI, M.; GOMEZ, M.; FREIRE, L. (Orgs.) (2003) Lecciones de Paulo Freire cruzando fronteras: experiencias que se completan. Buenos Aires: CLACSO, 2003.

STRECK, D. José Martí, Paulo Freire y la construcción de un imaginario pedagógico latinoamericano. Pedagogía y Saberes, n. 46, 2017. p. 55-63.

TORRES, C. A. A voz do biógrafo latino-americano. Uma biografia intelectual. En: GADOTTI, M. (Org.): Paulo Freire. Uma biobibliografía. São Paulo: Cortez. Instituto Paulo Freire, 1996.

TORRES, C. A. Paulo Freire e a agenda da educação Latino-Americana no Século XXI. Buenos Aires: CLACSO., 2001.

TORRES, R.M. Los múltiples Paulo Freire. 1997. Disponible online: :www.fronesis.org. (Última consulta: diciembre del 2019).

TRUJILLO, I. Freire entre nosotros. La Ventana: 24 de Febrero del 2005. Disponible online: http://laventana.casa.cult.cu). (Última consulta: diciembre del 2019).

\section{TESTIMONIOS:}


Canfux Gutiérrez, Jaime (2005): Cubano. Asesor en el Ministerio de Educación de Guinea Bissau 1978. Asesor en el Ministerio de Educación de la República de Nicaragua en 1979-80. Participante en la reunión de Paulo Freire con pedagogos cubanos en 1987. Entrevista realizada por el autor en La Habana, el 22 de noviembre del 2005.

Chávez Rodríguez, Justo (2006): Cubano. Asesor cubano en el Ministerio de Educación de la República de Nicaragua en 1979-80. Participante en la reunión de Paulo Freire con pedagogos cubanos en 1987. Entrevista realizada por el autor en La Habana, el 10 de febrero del 2006. Legón Padilla, Sara (2005): Cubana. Jefa de la asesoría cubana en el Ministerio de Educación de la República de Angola, 1976-78. Jefa de la asesoría cubana a la República Democrática de Sao Tomé y Príncipe, 1978. Entrevista realizada por el autor en La Habana, el 27 de diciembre del 2005.

Pinto Contreras, Rolando N (2007): Chileno. Director de Educación Campesina en el Gobierno de la Unidad Popular. Miembro de equipos de trabajo de Paulo Freire. Cooperante en la asesoría freiriana a la Cruzada Nacional de Alfabetización "Héroes y Mártires por la Liberación de Nicaragua" (CNA). Entrevista realizada por el autor en Halifax, Canadá el 9 de junio del 2007.

Thales, Josina (2008): Brasileña. Alumna de Paulo Freire en la Universidad de Pernambuco. Miembro del Movimiento de Cultura Popular. Profesora internacionalista en Cuba y Mozambique. Entrevistas realizadas con el autor en julio-agosto, 2008.

Ramírez Villasana, Luis Manuel (2006): Cubano. Combatiente internacionalista y asesor en el Ministerio de Educación de la República de Angola, 1976-79, Entrevista realizada por el autor en la Ciudad de La Habana, el 1 de marzo del 2006.

Recebido em 30 de abril de 2020

Aprovado em 10 de setembro de 2020

(c) (1) (8)(9) 